See Article page XXX.

\section{Commentary: So happy together}

\author{
Asvin M. Ganapathi, MD, and Matthew C. Henn, MD
}

Since the days of Halsted, surgeons have evolved in many significant ways. Training initially designed as a pyramid system to eliminate trainees has evolved into today's model where we work to train everyone matched into a program. Additionally, whereas all early surgeries began as large, open procedures, as a field we have developed into a group of individuals with a wide variety of skillsets-from procedures that most would not even consider surgery such as endoscopy and laparoscopic/robotic surgery, to those classic large, open operations. In all cases, advancements have provided patient benefit and are driven by innovation; competition from other specialties; or most importantly, collaboration with other specialties.

Paras and colleagues ${ }^{1}$ describe a single institutional experience with an treatment team for management of patients with endocarditis potentially requiring surgical intervention. The authors describe the creation of the Drug Use Endocarditis Team (DUET), a multidisciplinary group that handles the complexities experienced by patients with infective endocarditis secondary to drug use. The team, which at its core consists of surgeons, infectious disease physicians, cardiologists, and addiction medicine specialists, also involves neurosurgeons/neurologists, nurses, social workers, and others who meet monthly with potential for additional meetings ad hoc. Comparisons were made between patients pre-DUET $(\mathrm{n}=27)$ and post-DUET $(\mathrm{n}=19)$. The researchers found a significant decrease in time to addiction medicine consultation. Survey findings also demonstrated that DUET members believe the program

\footnotetext{
From the Division of Cardiac Surgery, Department of Surgery, The Ohio State University Wexner Medical Center, Columbus, Ohio.

Disclosures: Dr Ganapathi has provided consulting services for AbbVie Pharmaceuticals. Dr Henn has reported no conflicts of interest.

The Journal policy requires editors and reviewers to disclose conflicts of interest and to decline handling or reviewing manuscripts for which they may have a conflict of interest. The editors and reviewers of this article have no conflicts of interest.

Received for publication Nov 7, 2021; revisions received Nov 7, 2021; accepted for publication Nov 8, 2021.

Address for reprints: Asvin M. Ganapathi, MD, Division of Cardiac Surgery, Department of Surgery, The Ohio State University Wexner Medical Center, N-809 Doan Hall, 410 W 10th Ave, Columbus, OH 43210 (E-mail: Asvin.Ganapathi@osumc. edu).

J Thorac Cardiovasc Surg 202 $: 1-2$

$0022-5223 / \$ 36.00$

Copyright (c) 2021 by The American Association for Thoracic Surgery

https://doi.org/10.1016/j.jtcvs.2021.11.014
}

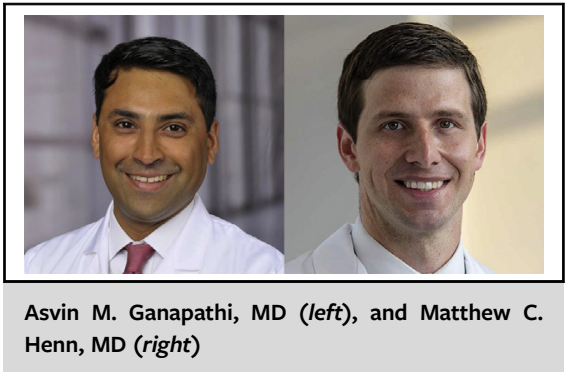

CENTRAL MESSAGE

Multidisciplinary teams continue

to be an important aspect of care for cardiac patients. Utilization of a multidisciplinary team for endocarditis patients will be important as therapies evolve.

improved several aspects of care for these patients. Although the study is underpowered to make any objective conclusions about the care of these endocarditis patients, it does discuss an important concept: Need for a multidisciplinary approach to patients with often-complex conditions.

As medicine has evolved, the lines between specialties, particularly within medicine and surgery, have blurred. Perhaps among the best examples is cancer care, where patients often come to a single building to see a surgeon, medical oncologist, and radiation oncologist all within a few hours and then have their case discussed amongst the involved parties soon afterward. In lung cancer care, multidisciplinary teams (MDTs) have been shown to improve time to diagnosis and ultimately treatment. ${ }^{2}$ In cardiac surgery, perhaps the most pronounced areas of collaboration amongst specialties are with transcatheter aortic valve replacement (TAVR) and cardiogenic shock. With TAVR, surgeons, cardiologists, and imaging specialists among others, discuss patients with potential valve deficiencies and consequently can offer the most appropriate therapy. This approach was believed to be essential to the early success of TAVR and remains part of the guidelines for patients being treated for valvular heart disease. ${ }^{3,4}$ With regard to cardiogenic shock, given the litany of medical, interventional, and surgical options available and often the need for rapid therapy, shock teams have emerged with success in minimizing mortality. ${ }^{5}$ The 
influence of a multidisciplinary approach is also seen with aortic surgery, benign esophageal disease, and many other pathologies in cardiothoracic surgery. In fact, the idea of an MDT in endocarditis has recently been described within a large hospital network in Germany with demonstration of a reduction in preintervention complications and postoperative mortality and stroke. ${ }^{6}$ As our field continues to evolve, the importance of MDTs will grow and likely encompass all aspects of care, ensuring that we will remain happy together with other specialties.

\section{References}

1. Paras ML, Wolfe SB, Bearnot B, Sundt TM, Marinacci L, Dudzinski DM, et al. Multidisciplinary team approach to confront the challenge of drug useassociated infective endocarditis. J Thorac Cardiovasc Surg. 2022. XXX: XXX.
2. Phillips WW, Copeland J, Hofferberth SC, Armitage JR, Fox S, Kruithoff M, et al. Lung Cancer Strategist Program: a novel care delivery model to improve timeliness of diagnosis and treatment in high-risk patients. Healthc (Amst). 2021;9: 100563.

3. Sintek M, Zajarias A. Patient evaluation and selection for transcatheter aortic valve replacement: the heart team approach. Prog Cardiovasc Dis. 2014;56: 572-82.

4. Nishimura RA, O'Gara PT, Bavaria JE, Brindis RG, Carroll JD, Kavinsky CJ, et al. 2019 AATS/ACC/ASE/SCAI/STS Expert Consensus Systems of Care document: a proposal to optimize care for patients with valvular heart disease: a joint report of the American Association for Thoracic Surgery, American College of Cardiology, American Society of Echocardiography, Society for Cardiovascular Angiography and Interventions, and Society of Thoracic Surgeons. J Am Coll Cardiol. 2019;73: 2609-35.

5. Papolos AI, Kenigsberg BB, Berg DD, Alviar CL, Bohula E, Burke JA, et al. Management and outcomes of cardiogenic shock in cardiac ICUs with versus without shock teams. J Am Coll Cardiol. 2021;78:1309-17.

6. Diab M, Franz M, Hagel S, Guenther A, Struve A, Musleh R, et al. Impact of an inhospital endocarditis team and a state-wide endocarditis network on perioperative outcomes. J Clin Med. 2021;10:4734. 